\title{
Case-control studies in cancer patients as a surveillance system of occupational exposure in the European Community
}

\author{
R J Rona, N A Taub, Siri Rasmussen
}

\begin{abstract}
Study Objective-The main aim was to detect known relationships between lung and blood cancers and various occupational exposures (using job titles as proxies) using a casecontrol design. The suitability of this system for routine surveillance could then be assessed.
\end{abstract}

Design-A case-control study was carried out in 1989.

Setting-Hospitals in eight European Community countries.

Subjects-Men aged 25 to 75 years with incident and prevalent cancer of the lung (190 cases), haematopietic system (210 cases), or gastrointestinal tract (245 controls) were studied.

Measurements and main results-The crude estimate of the overall odds ratio exposure (OR) for relevant occupational exposure of lung cancer relative to gastrointestinal cancer was $1 \cdot 20(95 \%$ confidence interval (CI) $0 \cdot 82,1 \cdot 77)$. In a logistic regression analysis adjusting for country, age at diagnosis, smoking, and alcohol consumption, the overall $O R$ was not greatly changed. A significant interaction of occupational exposure and age at diagnosis showed that lung cancer patients diagnosed at a younger age had a higher OR than patients diagnosed at an older age. Thus, the overall, insignificant result may have been due to a low reliability of occupational history in older age or to a selective mechanism related to age. The overall $O R$ for occupational exposure of cancer of the blood relative to gastrointestinal cancer was 0.88 $(95 \%$ CI $0.60,1.31)$. The logistic regression analysis did not alter these results.

Conclusion-A surveillance based on a casecontrol design using job titles would not be sensitive enough to detect possible occupational risks.

Division of

Community Health,

Department of Public

Health Medicine

United Medical and

Dental Schools, St

Thomas's Hospital, Lambeth Palace Road, London SE1 7EH

R J Rona

N A Taub

Siri Rasmussen

On behalf of the

European Community

Working Party whose

members are listed at the

end of this report

Correspondence to:

Dr R J Rona

Accepted for publication November 1992
In the first stage of the study a new questionnaire was developed and its acceptability, repeatability, and validity of occupational information was evaluated. ${ }^{1}$ It was concluded that the repeatability of industrial occupation information was satisfactory for research purposes $($ Kappa $=77 \%)$. The second stage aimed to determine the utility of case-control studies using a standardised questionnaire in detecting occupational exposure related to cancer.

Doll and Peto, ${ }^{2}$ in their review of avoidable risks of cancer in the US, emphasised the poor quality and limitations of current data in estimating the impact of occupational hazards on cancer deaths. They recommended a case-control design. Siemiatycki $e t a l^{3}$ provided theoretical arguments for case-control studies in this context. There are two commonly used controls for this type of study, community controls ${ }^{4}$ and patients with another severe disease, for example another type of cancer or chronic disease. ${ }^{5}$ In a surveillance system the collection of information would be greatly helped by selecting hospital controls. In an overview of this subject, Smith et $a l^{6}$ concluded that this design has the disadvantage of possible selection bias but the advantages of minimising recall and interview bias and of reducing costs. In this phase of the study the "cases" were patients with cancers known to have some relation to occupation; the "controls" were patients with types of cancers seldom associated with occupation. We wanted to assess whether in common cancers for which approximately 10 to $15 \%$ of cases can be ascribed to industrial exposure ${ }^{2}$ the appropriate association could be detected by a case-control study.

Methods and subjects

The study questionnaire was originally developed for earlier stages of the study ${ }^{1}$ and was revised to reduce deficiencies that had become apparent. The items included were the patient's age; marital status; smoking behaviour (duration, number of cigarettes a day, and details of any recent change in behaviour); alcohol consumption; occupational and industrial history ${ }^{7}$; and the ICD-O coding of their disease ${ }^{8}$ in terms of site, morphology, behaviour, differentiation, and year of diagnosis.

The data on occupation relate to the total number of jobs that the patient has performed and to details of his most recent job, his previous job, and any earlier job lasting at least 10 years. The details requested are duration of job (in years), the EC status group, and the industrial classification for the 1981 census in Britain. ${ }^{7}$ The industrial classification was based on a four digit classification; the first two digits give the class and the composite four digit number gives the activity.

The questionnaire was administered to male patients aged $25-75$ years. The rationale for the case-control design of the study was to ascertain 
whether such a design would be robust enough to identify well established occupational hazards. The suggested number of cases in each country was 25 patients with lung cancer and 30 patients with cancer of the haematopoietic system (nonHodgkin's lymphoma, Hodgkin's disease, or leukaemia). The controls were 35 patients with stomach, colon, or rectal cancer, diseases that have rarely been reported to be related to an occupational hazard.

The sample size for lung cancer cases was estimated by assuming that $24 \%$ of the control group would be exposed to occupations associated with lung cancer (taken from the corresponding rate among bladder cancer patients in previous stages of the project). For a relative risk of 2.0 to be detected with an $80 \%$ chance with a two-sided test at the $5 \%$ significance level, the minimum sample required is 149 subjects in each group. If eight EC countries take part in the study approximately 20 patients with lung cancer and 20 control patients in each country will be required ( 25 patients in each group will be required to allow for adjustments such as smoking). The sample size for patients with cancer of the haematopoietic system was based on a $16 \%$ proportion of the control group being exposed to occupations associated with blood cancers, likewise estimated from the rate in bladder cancer patients. A relative risk of $2 \cdot 0$ can be detected with a sample of 187 subjects in each group as the minimum sample with an $80 \%$ chance in a two sided test at a $5 \%$ significance level. If eight EC countries take part in the study, 25 patients with cancer of the blood and 25 control patients (a total of 30 patients in each group to allow for adjustments) will be required. The decision to include lung cancer patients as cases was taken despite the very strong relation between this cancer and smoking behaviour, because of the sheer number of cases and the confirmation that in industries known to be a hazard for lung cancer this risk still persists. ${ }^{9}$

A review of the published reports was carried out to identify the occupations that were currently reported to be related to the diseases of the cases. The occupations associated with lung cancer are listed in table I, those associated with cancers of the blood are listed in table II. The tables give the occupation, coding, and relevant references. In

Table I Significant associations between lung cancer and occupation

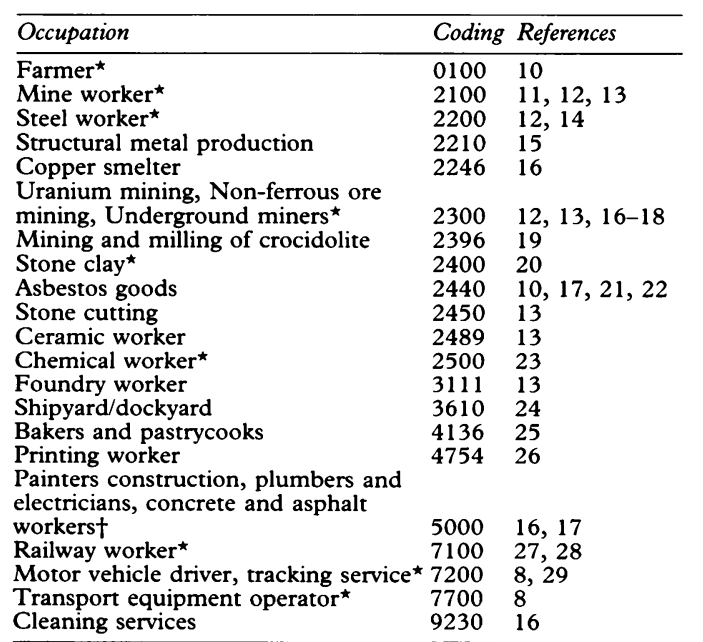

*These are occupation classes, ie include all occupations starting with the two digits

tThis is a division class
Table II Associations between cancer of the haematopoietic system and occupation

\begin{tabular}{|c|c|c|}
\hline Occupation & Coding & References \\
\hline 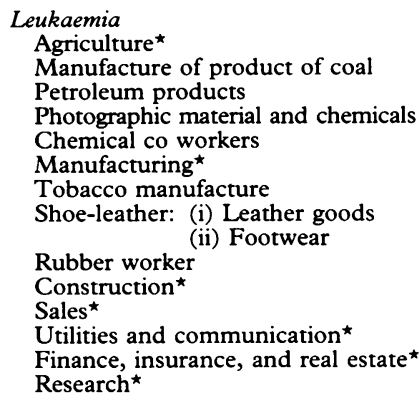 & $\begin{array}{l}100 \\
1115 \\
2512 \\
2591 \\
2599 \\
3100-3700 \\
4290 \\
4420 \\
4510 \\
4812 \\
5000 \\
6400-6600 \\
7100-7900 \\
8100-8300 \\
9400\end{array}$ & $\begin{array}{l}30 \\
30 \\
30,31 \\
31 \\
31 \\
32 \\
30 \\
31 \\
31 \\
31 \\
32 \\
32 \\
32 \\
32 \\
30\end{array}$ \\
\hline $\begin{array}{l}\text { Hodgkin's disease } \\
\text { Farmers } \\
\text { Fisherman } \\
\text { Cementer } \\
\text { Glass } \\
\text { Pottery } \\
\text { Chemical processing } \\
\text { Dyer } \\
\text { Chemist sprayer } \\
\text { Photography } \\
\text { Spinning, weaving } \\
\text { Leather worker } \\
\text { Leather goods } \\
\text { Woodmakers } \\
\text { Carpenter } \\
\text { Plastic worker }\end{array}$ & $\begin{array}{l}0100 \\
0300 \\
2420 \\
2478-2479 \\
2489 \\
2500 \\
2516 \\
2551 \\
2591 \\
4321 \\
4410 \\
4420 \\
4600 \\
4630 \\
4836\end{array}$ & $\begin{array}{l}33,34 \\
34 \\
34 \\
30,35 \\
35 \\
35 \\
34 \\
35 \\
34 \\
30 \\
34 \\
34 \\
34,36 \\
37 \\
34\end{array}$ \\
\hline $\begin{array}{l}\text { Non-Hodgkin's lymphoma } \\
\text { Agriculture } \\
\text { Forestry }^{\star} \\
\text { Waterworks and supply }^{\star} \\
\text { Manufacturing of non-metallic } \\
\text { products }{ }^{\star} \\
\text { Benzene } \\
\text { Canning, preserving and processing } \\
\text { of fish etc. } \\
\text { Leather worker } \\
\text { Fencing work }\end{array}$ & $\begin{array}{l}2400 \\
2512 \\
4115-4150 \\
4400 \\
4630\end{array}$ & $\begin{array}{l}38 \\
33 \\
30\end{array}$ \\
\hline
\end{tabular}

$\star$ These are occupation classes, ie include occupations starting with the two digits

relation to lung cancer, we included only those references that were based on data from industrially developed countries and which quoted a confidence interval for the estimated risk. With regard to cancer of the blood, we relaxed the requirement that the relevant report should quote a confidence interval for the risk, since there are fewer relevant papers on cancer of the blood than on lung cancer. Proportional mortality ratio studies were excluded. These can be misleading as differences in mortality from other cancers may influence the association between exposure and the relevant disease.

In the statistical analyses, subjects were considered exposed to a high risk occupation if they had worked in any of the relevant occupations for at least three years (see tables I and II). Odds ratios (ORs) were used to estimate the association of occupational exposure with lung cancer and with blood cancer, using gastrointestinal cancer patients as controls. Where there are (a) exposed cases, (b) unexposed cases, (c) exposed controls, and (d) unexposed controls, the crude, unadjusted estimate of the odds ratio is given by $\mathrm{OR}=\underline{\mathrm{ad}}$. bc

Confidence intervals were calculated using the formula:

$$
\operatorname{Var}\left[\log _{e}(O R)\right]=\frac{1}{a}+\frac{1}{b}+\frac{1}{c}+\frac{1}{d}
$$

and the assumption that $\log _{e}(\mathrm{OR})$ is normally distributed. Logistic regression models ${ }^{39}$ were 
developed to adjust for the suspected confounding variables: age at diagnosis, country, amount of smoking, alcohol consumption, and the dates of diagnosis and of interview (to distinguish between prevalent and incidence cases). The variables for the analysis of lung cancer were divided into groups of approximately equal size as follows:

Age at diagnosis: $25-56$ years, 57-61 years, 62-66 years, and 67 years or over;

Length between time of diagnosis and interview: up to 36 months or more than 36 months;

Length of time smoking: 0 years, 1-34 years,

35-44 years and more than 44 years;

Cigarette consumption per day: $0,1-19,20-24$, and more than 24 ;

Alcohol consumption (g/week): 0, 1-120, $121-$ 299, and more than 299;

Age at time of survey: $25-56$ years, $57-61$ years, 62-66 years, and more than 66 years;

EC job status grouped into eight categories as a proxy for socioeconomic group;

Which of the eight EC countries.

The exposure variable was divided into less than 36 months or at least 36 months in the relevant high risk occupations.

The variables for the analysis of blood cancer were divided in a similar manner except that for age at diagnosis the classes were 21-49 years, $50-58$ years, $59-64$ years, and more than 64 years, since patients with this cancer were younger than for lung cancer.

\section{Results}

DESCRIPTION OF THE SAMPLE

Table III gives the distribution of patients in relation to type of cancer and country after excluding 41 patients who did not satisfy the entry criteria. The age distributions for patients with lung cancer and gastrointestinal cancer were very similar both between countries and between these two types of cancer. Patients with cancer of the blood were on average younger than patients in

Table III Distribution of patients in relation to mean (SD) age (years), type of cancer, and country

\begin{tabular}{|c|c|c|c|c|c|c|}
\hline \multirow[b]{2}{*}{ Country } & \multicolumn{2}{|c|}{$\begin{array}{l}\text { Gastrointestinal } \\
\text { cancer }\end{array}$} & \multicolumn{2}{|c|}{ Lung cancer } & \multicolumn{2}{|c|}{ Blood cancer } \\
\hline & No & Mean (SD) & $\overline{N o}$ & Mean (SD) & No & Mean $(S D)$ \\
\hline $\begin{array}{l}\text { Belgium } \\
\text { Denmark } \\
\text { France } \\
\text { Germany } \\
\text { Ireland } \\
\text { Italy } \\
\text { United Kingdom } \\
\text { Spain }\end{array}$ & $\begin{array}{l}16 \\
33 \\
35 \\
35 \\
21 \\
33 \\
36 \\
36\end{array}$ & $\begin{array}{l}59 \cdot 8(10 \cdot 1) \\
59 \cdot 8(6 \cdot 8) \\
61 \cdot 1(8 \cdot 1) \\
58 \cdot 9(9 \cdot 9) \\
56 \cdot 0(13 \cdot 3) \\
58 \cdot 7(7 \cdot 4) \\
62 \cdot 2(8 \cdot 9) \\
61 \cdot 4(8 \cdot 3)\end{array}$ & $\begin{array}{l}25 \\
21 \\
24 \\
25 \\
19 \\
28 \\
25 \\
23\end{array}$ & $\begin{array}{l}61 \cdot 4(7 \cdot 4) \\
60 \cdot 9(6 \cdot 4) \\
59 \cdot 5(7 \cdot 3) \\
61 \cdot 1(6 \cdot 1) \\
60 \cdot 4(8 \cdot 9) \\
58 \cdot 1(8 \cdot 1) \\
60 \cdot 9(7 \cdot 7) \\
64 \cdot 8(6 \cdot 8)\end{array}$ & $\begin{array}{l}28 \\
25 \\
25 \\
27 \\
19 \\
31 \\
31 \\
24\end{array}$ & $\begin{array}{l}57 \cdot 3(10 \cdot 9) \\
50 \cdot 1(15 \cdot 1) \\
44.0(13.9) \\
53.5(13 \cdot 2) \\
51.5(14.5) \\
52.0(11.9) \\
57.2(11.2) \\
55.6(13.9)\end{array}$ \\
\hline Total & 245 & $60 \cdot 0(9 \cdot 0)$ & 190 & $60 \cdot 8(7 \cdot 5)$ & 210 & $52 \cdot 8(13 \cdot 4)$ \\
\hline
\end{tabular}

Table IV Mean (SD) numbers of years accounted for in the occupational history explored in the study

\begin{tabular}{|c|c|c|c|c|c|c|}
\hline \multirow[b]{2}{*}{ Country } & \multicolumn{2}{|c|}{$\begin{array}{l}\text { Gastrointestinal } \\
\text { cancer }\end{array}$} & \multicolumn{2}{|c|}{ Lung cancer } & \multicolumn{2}{|c|}{ Blood cancer } \\
\hline & No & Mean $(S D)$ & No & Mean $(S D)$ & No & Mean (SD) \\
\hline $\begin{array}{l}\text { Belgium } \\
\text { Denmark } \\
\text { France } \\
\text { Germany } \\
\text { Ireland } \\
\text { Italy } \\
\text { United Kingdom } \\
\text { Spain }\end{array}$ & $\begin{array}{l}16 \\
33 \\
35 \\
35 \\
21 \\
33 \\
36 \\
36\end{array}$ & $\begin{array}{l}34 \cdot 4(28 \cdot 5) \\
34 \cdot 9(8 \cdot 4) \\
32 \cdot 0(11 \cdot 3) \\
33 \cdot 0(9 \cdot 9) \\
31 \cdot 4(12 \cdot 5) \\
38 \cdot 8(8 \cdot 2) \\
36 \cdot 3(10 \cdot 8) \\
36 \cdot 1(10 \cdot 4)\end{array}$ & $\begin{array}{l}25 \\
21 \\
24 \\
25 \\
19 \\
28 \\
25 \\
23\end{array}$ & $\begin{array}{l}36 \cdot 5(11 \cdot 5) \\
36 \cdot 5(9 \cdot 7) \\
28 \cdot 9(11 \cdot 6) \\
37 \cdot 9(8 \cdot 0) \\
28 \cdot 8(16 \cdot 4) \\
36 \cdot 6(10 \cdot 3) \\
34 \cdot 0(11 \cdot 4) \\
43 \cdot 2(8 \cdot 4)\end{array}$ & $\begin{array}{l}28 \\
25 \\
25 \\
27 \\
19 \\
31 \\
31 \\
24\end{array}$ & $\begin{array}{l}36 \cdot 6(21 \cdot 4) \\
27 \cdot 4(15 \cdot 9) \\
20 \cdot 4(13.3) \\
26 \cdot 1(13.9) \\
28 \cdot 1(17 \cdot 0) \\
30 \cdot 7(11 \cdot 3) \\
33 \cdot 2(9 \cdot 8) \\
34 \cdot 3(13 \cdot 3)\end{array}$ \\
\hline Total & 245 & $34 \cdot 8(12 \cdot 2)$ & 190 & $35.5(11 \cdot 6)$ & 210 & $29 \cdot 8(15 \cdot 3)$ \\
\hline
\end{tabular}

the other two groups. In general, patients with Hodgkin's disease were the youngest (mean age $46 \cdot 8$ years), while patients with lymphoma and leukaemia had mean ages of 54.0 and 53.4 years respectively. In terms of cancer site, the distributions of patients with a gastrointestinal tract cancer were as follows: stomach $(n=49)$, small intestine $(n=1)$, colon $(n=102)$, and rectum or rectosigmoid junction $(n=77)$. Belgian patients could not be included in the distributions by site as they were given a diagnosis without further classification according to site or morphology.

The types of cancer of the blood were: lymphomas not otherwise specified or diffuse $(n=57)$, lymphomas (nodular or folicular) $(n=23)$, Burkitt's lymphoma $(n=1)$, leukaemias $(n=55)$, reticulosarcoma $(n=5)$, and Hodgkin's disease $(n=41)$.

Most patients were diagnosed in the last year of the study. For gastrointestinal cancer 114 patients were diagnosed less than a year before interview, 68 between one and three years before interview, and 40 more than three years before interview. Similar figures for lung cancer were 128,11 , and 19 respectively and for cancer of the blood 84,40 , and 49 respectively. This information was not available for 92 patients, most of whom were from Belgium.

For each country in the study, both the length of time smoking and the number of cigarettes smoked were higher in patients with lung cancer than in patients with gastrointestinal cancer or cancer of the blood. When patients who smoked pipes or cigars were included, only one patient in the lung cancer group was a non-smoker. Smoking was also highly prevalent in the group of patients with cancer of the gastrointestinal tract. Even in patients with cancer of the blood, the observed percentage of non-smokers was low in comparison with that often reported in the population.

Patients with lung cancer had on average a higher level of alcohol intake than patients with other types of cancer. The variation in alcohol consumption between countries was very large, ranging from $88 \mathrm{~g}$ per week in Britain to $328 \mathrm{~g}$ per week in Germany.

Table IV gives the number of years accounted for by the three jobs that patients were asked to describe - that is the last job, previous job, and earlier jobs lasting more than 10 years. These occupations together represented approximately $93 \%$ of the total time that patients had spent in employment. On average, the jobs represented approximately 35 years' work for patients with gastrointestinal cancer or cancer of the lung and 30 years for patients with blood cancer. The SDs were, however, very large, indicating that for some patients the number of years in any employment was low.

\section{CASE-CONTROL ANALYSIS}

Lung cancer (cases) and gastrointestinal tract cancer (controls)

Table $\mathrm{V}$ gives the frequencies of cases and of controls in relation to country and exposure category. The overall unadjusted estimate of OR for occupational exposure was not significantly different from $1, \mathrm{OR}=1.20(95 \% \mathrm{CI} 0 \cdot 82,1 \cdot 77)$. Although the unadjusted ORs varied widely in 
Table $V$ Numbers occupationally exposed and unexposed for cases and controls in relation to country for lung cancer (cases) and gastrointestinal tract cancer (controls)

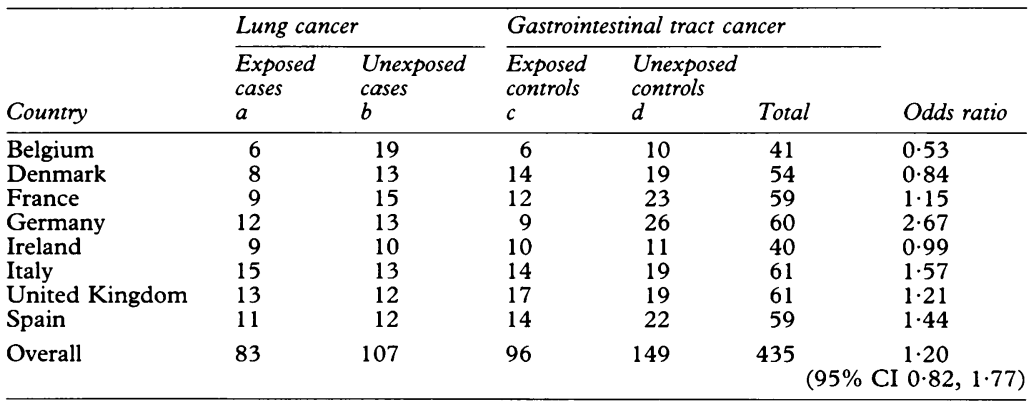

Table VI Logistic regression model for lung cancer and gastronintestinal cancer: estimated coefficients, $b$ of smoking behaviour

\begin{tabular}{|c|c|c|c|c|c|}
\hline & No & $b$ & $s e(b)$ & Odds ratio & $95 \% C I$ \\
\hline $\begin{array}{l}\text { Time smoking }(y) \text { : } \\
\text { Non-smokers } \\
1-34 \\
35-44 \\
45+\end{array}$ & $\begin{array}{r}39 \\
133 \\
129 \\
134\end{array}$ & $\begin{array}{l}0.00 \\
2 \cdot 45 \\
2 \cdot 93 \\
3 \cdot 80\end{array}$ & $\begin{array}{l}- \\
1 \cdot 16 \\
1 \cdot 16 \\
1 \cdot 17\end{array}$ & $\begin{array}{r}1 \cdot 00 \\
11 \cdot 54 \\
18 \cdot 70 \\
44 \cdot 70\end{array}$ & $\begin{array}{l}- \\
1 \cdot 20,111 \cdot 67 \\
1 \cdot 94,179 \cdot 43 \\
4 \cdot 54,440 \cdot 68\end{array}$ \\
\hline $\begin{array}{l}\text { Daily cigarette cons } \\
\quad \text { Non-smokers } \\
1-19 \\
20-24 \\
25+\end{array}$ & $\begin{array}{r}62 \\
99 \\
123 \\
151\end{array}$ & $\begin{array}{l}0 \cdot 00 \\
0.03 \\
0 \cdot 61 \\
1.02\end{array}$ & $\begin{array}{l}- \\
0.57 \\
0.56 \\
0.56\end{array}$ & $\begin{array}{l}1 \cdot 00 \\
1 \cdot 03 \\
1 \cdot 84 \\
2 \cdot 78\end{array}$ & $\begin{array}{l}- \\
0 \cdot 33,3 \cdot 16 \\
0 \cdot 61,5 \cdot 49 \\
0.93,8 \cdot 26\end{array}$ \\
\hline
\end{tabular}

individual countries, from 0.53 (Belgium) to $2 \cdot 67$ (Germany), none were significantly different from 1 ( $p>0.05)$.

Logistic regression analysis was carried out to adjust the OR for the potentially confounding variables, giving the estimate $\mathrm{OR}=0.99$ (95\% CI $0.63,1.58)$. The only independent factors that were significantly associated with case-control status were: duration of smoking $(p<0.001)$, cigarette consumption $(\mathrm{p}<0.01)$, and job status $(\mathrm{p}<0.05)$ (table VI). Two-way interaction terms between smoking and drinking were then included in the model and retained, although their overall significance was marginal $(p=0.05)$.

The presence of any effect modifications was now assessed by backwards stepwise deletion of the interaction terms between each independent factor and occupational exposure. The only factor found to modify the association of high risk jobs with lung cancer was the patient's age at diagnosis. Although this effect is not highly significant $(p=0.03)$, a gradient where occupational exposure seems to increase the risk for younger men but to decrease the risk for older men was shown (table VII).

Blood cancer (cases) and gastrointestinal tract cancer (controls)

The overall unadjusted estimate of OR was not significantly different from $1(\mathrm{OR}=0.88$ (95\% CI $0.60,1.31)$ ). As with lung cancer, the variation in unadjusted ORs in different countries was wide but was not statistically significant (table VIII).

In the logistic regression analysis, adjustment was made for the same set of potentially confounding variables as for the previous analysis of lung cancer except for time smoking because this variable would be strongly associated with age.

Table VII Logistic regression model for lung cancer and gastrointestinal cancer: age specific odds ratios of occupational exposure

\begin{tabular}{lrll}
\hline Age $(y)$ & No & Odds ratio & $95 \%$ CI \\
\hline $22-56$ & 132 & $1 \cdot 76$ & $0 \cdot 73,4 \cdot 22$ \\
$57-61$ & 95 & $1 \cdot 58$ & $0 \cdot 58,4 \cdot 30$ \\
$62-66$ & 126 & $0 \cdot 73$ & $0 \cdot 29,1 \cdot 82$ \\
$67+$ & 82 & $0 \cdot 25$ & $0 \cdot 08,0 \cdot 78$ \\
\hline
\end{tabular}

The only significant confounder in the model was age at diagnosis $(\mathrm{p}<0.001)$ (table IX). Interaction terms between smoking and drinking were then included in the model, although they were not significant $(p>0.05)$.

The search for effect modification did not identify any factor that interacted with occupational exposure.

\section{Discussion}

The time available for recruiting patients into the study was only four months. Most countries complied with the number of patients suggested in the protocol. Although 41 patients had to be excluded from the analysis because they did not fulfil the protocol requirements, some departures from the rules for age and diagnosis were permitted. Thus, reticulosarcoma was included within the definition of lymphoma. After excluding the patients that did not fulfil the requirements, the number of patients for the analysis was $90 \%$ of the target number.

In general, the percentage of non-smokers was very low for all types of cancers, although, as expected, patients with a lung cancer had higher tobacco consumption levels. In terms of alcohol intake, there were very large differences between countries. There are several sources of artefact: the wide variation in alcohol content of beverages, the variation between countries in terms of the size of glass used commercially and in the home, and the conversion of beverage consumption (as given in the questionnaire) to that of total alcohol content. We minimised the second and third types of artefact by allowing for different sizes of glasses and by standardising for alcohol content by beverage.

The occupational history explored in this study accounted for around $90 \%$ of the participants' total time in employment. The reasons for choosing lung and blood cancers as the case diseases in the study were: (i) they were sufficiently common, (ii) several reports of their relation with occupation were available, and (iii) they had contrasting characteristics. Lung cancer is a fairly homogeneous entity characterised by short survival and it is strongly related to tobacco consumption. Cancer of the blood consist of a very large number of disorders, each of them low in frequency and with a survival time that can be large. A cure can be achieved for some of these blood disorders, such as Hodgkin's disease.

The controls used in this study include both an aggressive type of cancer, such as stomach cancer, and a cancer with a fairly good survival such as cancer of the colon. In general, the published reports available have failed to find many occupations related to this type of cancer.

The results from the case-control analysis of lung cancer and gastrointestinal cancer patients indicated no overall risk as a result of occupational exposure, which indicates that this type of design is not sufficiently sensitive for a surveillance system. There was a significant interaction between occupational exposure and age at diagnosis; the $O R$ for the younger patients was higher than that for the older patients. There are several possible explanations - chance finding, artefact, a selective factor, or a real difference due to some change in 
Table VIII Crude data for blood cancer (cases) and gastrointestinal tract cancers (controls)

\begin{tabular}{|c|c|c|c|c|c|c|}
\hline Country & $\begin{array}{l}\text { Exposed } \\
\text { cases } \\
a\end{array}$ & $\begin{array}{l}\text { Unexposed } \\
\text { cases } \\
b\end{array}$ & $\begin{array}{l}\text { Exposed } \\
\text { controls } \\
c\end{array}$ & $\begin{array}{l}\text { Unexposed } \\
\text { controls } \\
d\end{array}$ & No & Odds ratio \\
\hline $\begin{array}{l}\text { Belgium } \\
\text { Denmark } \\
\text { France } \\
\text { Germany } \\
\text { Ireland } \\
\text { Italy } \\
\text { United Kingdom } \\
\text { Spain }\end{array}$ & $\begin{array}{l}10 \\
17 \\
20 \\
21 \\
18 \\
13 \\
19 \\
17\end{array}$ & $\begin{array}{r}18 \\
8 \\
5 \\
6 \\
1 \\
18 \\
12 \\
7\end{array}$ & $\begin{array}{r}7 \\
27 \\
22 \\
26 \\
15 \\
10 \\
30 \\
27\end{array}$ & $\begin{array}{r}9 \\
6 \\
13 \\
9 \\
6 \\
23 \\
6 \\
9\end{array}$ & $\begin{array}{l}44 \\
58 \\
60 \\
62 \\
40 \\
64 \\
67 \\
60\end{array}$ & $\begin{array}{l}0 \cdot 71 \\
0 \cdot 47 \\
2 \cdot 36 \\
1 \cdot 21 \\
7 \cdot 20 \\
1 \cdot 66 \\
0 \cdot 32 \\
0 \cdot 81\end{array}$ \\
\hline Overall & 135 & 75 & 164 & 81 & 455 & $\begin{array}{c}0.88 \\
(95 \% \text { CI } 0.60,1.31)\end{array}$ \\
\hline
\end{tabular}

Table IX Logistic regression model for blood cancer and gastrointestinal: cancer estimated coefficients, $b$, of age effect

\begin{tabular}{llllll}
\hline $\begin{array}{l}\text { Age at } \\
\text { diagnosis (y) }\end{array}$ & No & \multicolumn{1}{c}{$b$} & se(b) & Odds ratio & $95 \%$ CI \\
\hline$<50$ & 120 & $0 \cdot 00$ & - & $1 \cdot 00$ & - \\
$50-58$ & 117 & $-1 \cdot 23$ & $0 \cdot 29$ & $0 \cdot 29$ & $0 \cdot 16,0 \cdot 52$ \\
$59-64$ & 108 & $-1 \cdot 81$ & $0 \cdot 31$ & $0 \cdot 16$ & $0 \cdot 09,0 \cdot 30$ \\
$64+$ & 110 & $-1 \cdot 47$ & $0 \cdot 31$ & $0 \cdot 23$ & $0 \cdot 13,0 \cdot 42$ \\
\hline
\end{tabular}

the nature of occupational exposure over time. It seems that differential reliability and selection over time are the most plausible explanations for this finding. The differential reliability of occupational history (if it were shown in other studies) would suggest that patients in this type of study be restricted to a narrow age range, although this would increase the difficulty of recruitment. This may be a valid finding for lung cancer and should not therefore affect the general design of surveillance.

The case-control analysis of blood cancers and gastrointestinal cancers did not show a significant overall risk due to occupational exposure either.

The study has been helpful in identifying a number of problems with this sort of surveillance system. It was a great advantage that in this study we could group together the many occupations already known to be associated with a type of cancer. In a full surveillance system of occupational exposure, however, each separate occupation will have to be tested for an association with a disease. The diversity of occupations in the modern world means that a very large number of patients will be required.

In this study the control group was mixed and would be expected to be a reasonable group to choose for this purpose. However, there may be two caveats. Some of these cancers are associated with lower socioeconomic status groups and would include a higher proportion of patients in semiskilled and unskilled occupations than would, say, cancers of the blood. We checked this possibility by including EC job status (as a proxy for socioeconomic background) in the logistic modelling. In a surveillance programme there may be an advantage in using an additional control group which is not known to be associated with social status.

The case-control study related to blood cancers illustrated another possible limitation of this sort of system. Patients with cancer of the blood are younger than patients with other types of cancer. We have adjusted for age in our analysis but other characteristics that are more prevalent in younger than in older patients, or vice versa, might have escaped adjustment.

In conclusion, the study has shown that the power of a surveillance system for occupational exposure based on a case-control design would be rather low and, if implemented, it should include a very large number of collaborating institutions in each country. We fear that many of the true associations will be missed because of the very large number of occupations in modern societies. One of the possible problems, as pointed out by Siemiatycki et $a l^{3}$ is that job title covers a group of workers whose activities and exposures are heterogenous. A risk may go undetected because only a subgroup in a job title may have been exposed to a carcinogen.

Members of the working party were as follows: Belgium-Dr M Kornitzer (Laboratoire d'Epidemiologie et de Medicine Sociale, Universite Libre de Bruxelles), Dr P De Vuyst (Hopital Erasme, Universite Libre de Bruxelles). Denmark-Dr J Mosbech (Chairman) (National Board of Health), Dr M Anderson (Institute of Cancer Epidemiology). France-Professor R Pariente (Clinique Pneumologique de l' Hôpital Beaujon), Dr F Neukirch (Laboratoire de Physiopathologie Respiratoire, Hôpital Beaujon). Germany -Dr C Dutting (Institut für Soziale Medizin, Freie Universitat Berlin), Professor Gustar Schake (Institute of Occupational medicine, Freie Universitet Berlin). Ireland-Dr P Kirke (The Health Research Board), Dr B Herity (Department of Community Medicine and Epidemiology, University College). Italy-Professor S Marinoni (Istituto de Scienze Sanitarie Applicate, Universita degli Study di Pavia), Dr L Casali (Presidio Pneumotisiologico). Netherlands-Dr D J van Puter Nederlands Instituut voor Praeventieve Gezondheidszorg TNO), Dr H P A van de Walter (Nederlands Instituut voor Praeventieve Gezondheidszorg TNO). Spain-Dr S Moncada (Centre de Salut Laboral, Institut Municipal de Salut), Dr A Arias (Servei d'Informacioni Sanitaria Institut Municipal de la Salut). United Kingdom-Professor W W Holland (Department of Public Health Medicine, UMDS), Dr M Farebrother (Medway Hospital); Dr R J Rona (Department of Public Health Medicine, UMDS).

1 Rona RJ, Mosbech J. Validity and repeatability of self reported occupational and industrial history from patients reported occupational and industrial history from pation

in EEC countries. Int $\mathcal{F}$ Epidemiol $1989 ; 18: 674-9$.

Doll R, Peto R. The causes of cancer. Quantitative estimates
of avoidable risks of cancer in the United States today. $\mathcal{F}$ Natl of avoidable risks of cancer in the

3 Siemiatycki J, Nicholas ED, Fabry J, Cooper JA. Discovering carcinogens in the occupational environment: a novel epidemiologic approach. $\mathcal{F}$ Natl Cancer Inst 1981; 66 217-25.

4 Hoover RN, Hartge Strasser P. Artificial sweeteners and human bladder cancer. Lancet 1980; i: 837-840.

5 Acheson ED, Cowdell RH, Rang E. Adenocarcinoma of the nasal cavity and sinuses in England and Wales. $\mathrm{Br} F$ Ind Med 1972; 29: 21-30.

6 Smith AH, Pearce NE, Callas PW. Cancer case-control studies with other cancers as controls. Int $\mathcal{F}$ Epidemiol 1988 17: 298-306.

7 Office of Population Censuses and Surveys. Classification of occupations 1980. London: HMSO, 1980.

8 World Health Organisation. International classification of disease for oncology. ICD-O. Geneva: WHO, 1976.

disease for oncology. $C D-O$. Geneva. WHO, 1976 . factors of lung cancer in a French case-control study. $B r \mathcal{F}$ factors of lung cancer in a
Ind Med 1988; 45: 231-3.

10 McDuffie HH, Klaassen DJ, Cockcroft DW, Dosman JA. Farming and exposure to chemicals in male lung cancer Farming and exposure to chemicals in male lung cancer
patients and their siblings. $\mathcal{f}$ Occup Med 1988; 30: 55-9.

patients and their siblings. F Occup Med 1988; 30: $55-9$.
Dave SK, Edling C, Jacobson P, Axelson O. Occupation, Dave SK, Edling C, Jacobson P, Axelson O. Occupation,
smoking and lung cancer. Br $\mathcal{F}$ Ind Med 1988; 45: 790-2. smoking and lung cancer. $B r f$ Ind Med 1988 ; 45: 790-2.

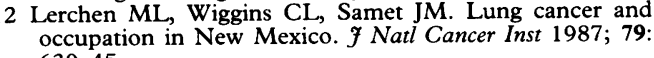

13 Lynge E, Kurppa K, Kristofersen L, Malker H, Sauli H. Silica dust and lung cancer: results from the Nordic occupational mortality and cancer incidence registers. $\mathscr{f}$ Natl Cancer Inst 1986; 77: 883-9.

14 Beaumont JJ, Leveton K, Knox K, et al. Lung cancer mortality in workers exposed to sulfuric acid mist and othe acid mists. F Natl Cancer Inst 1987; 79: 911-21.

15 Ronco G, Ciccone G, Mirabelli D, Troia B, Vineis P. Occupation and lung cancer in two industrialized areas of northern Italy. Int $\mathcal{f}$ Cancer 1988; 41: 345-58.

16 Damber LA, Larsson LG. Occupation and male lung cancer a case-control study in northern Sweden. Br f Ind Med 1987 44: $446-53$. 
17 Damber LA, Larsson LG. Underground mining, smoking and lung cancer: a case-control study in the iron ore municipalities of northern Sweden. $f$ Natl Cancer Inst 1985; 74: $1207-13$.

18 Samet JM, Pathak DER, Morgan MV, Marbury MC, Key $\mathrm{CR}$ et al. Radon progeny exposure and lung cancer risk in New Mexico uranium miners: a case-control study. Health New Mexico uranium miner.

19 Armstrong BK, De Klerk NH, Musk AW, Hobbs MST. Mortality in miners and millers of crocidolite in Western Australia. Br f Ind Med 1988;

20 Buiatti E, Kriebel D, Geddes M, Santucci M, Pucci N. A case control study of lung cancer in Florence, Italy. Occupational risk factors. $\mathcal{F}$ Epidemiol Community Health 1985; 39: 244-50.

21 Gardner MJ, Powell CA, Gardner A, Winter PD, Fletche AC. Continuing high lung cancer mortality among examosite asbestos factory workers and a pilot study of individual anti-smoking advice. $\mathcal{F}$ Soc Occup Med 1988; 38 69-72.

22 Vineis P, Thomas T, Hayes RB, et al. Proportion of lung cancers in males, due to occupation, in different areas of the USA. Int $\mathcal{f}$ Cancer 1988; 42: 851-6.

23 Bond GG, Flores GH, Shellenberger RJ, Cartmill JB, Fishbeck WA, Cook RR. Nested case-control study of lung cancer among chemical workers. Am $\mathcal{F}$ Epidemiol 1986; 124: 53-66.

24 Sanden A, Naslund P, Jarvholm B. Mortality in lung and gastro-intestinal cancer among shipyard workers. Int Arch gastro-intestinal cancer among shipyard
Occup Environ Health 1985; 55: 277-83.

25 Wicksell L, Carstensen JM, Eklund G, Gustafsson JA. Lung cancer incidence among Swedish bakers and pastry cooks: geographical variation. Scand 7 Soc Med 1988; 16: 183-6.
Schoenberg JB, Stemhagen A, Mason TJ, Patterson J, Bill J, Altman R. Occupation and lung cancer risk among New Jersey white males. F Natl Cancer Inst 1987; 79: 13-21.

27 Garshick E, Schenker MB, Munoz A, et al. A retrospective cohort study of lung cancer and diesel exhaust exposure in railroad workers. Am Rev Respir Dis 1988; 137: 820-5.
28 Garshick E, Schenker MB, Munoz A, et al. A case-control study of lung cancer and diesel exhaust exposure in railroad workers. Am Rev Respir Dis 1987; 135: 1242-8.

29 Damber L, Larsson LG. Professional driving, smoking, and lung cancer: a case referent study. Br f Ind Med 1985; 42: lung cancer $246-52$.

30 Olsen J, Jensen OM Occupation and risk of cancer in Denmark. Scand $\mathcal{f}$ Work Environ Health 1987; 13(suppl 1):

31 Linet MS. The leukaemias: epidemiological aspects. New York. Oxford University Press, 1985.

32 Williams RR, Stegens NL, Goldsmith JR. Associations of cancer site and type with occupation and industry from the third national cancer interviews. F Natl Cancer Inst 1977; 59. 1143-85.

33 Dubrow R, Poulson JO, Indian RW. Farming and malignan lymphoma in Hancock Country, Ohio. Br $\mathcal{F}$ Ind Med 1989 45: $25-8$.

34 Vianna NL, Polan A. Lymphomas and occupational bezene exposure. Lancet 1979; i: 1394-5.

35 Olsson $\mathrm{H}$, Brandt $\mathrm{L}$. Occupational handling of chemicals preceding Hodgkin's disease in men. Br 7 Ind Med 1979; 279: $580-1$.

36 Fonte R, Grigis L, Grigis P, Franco G. Chemicals and Hodgkin's disease. Lancet 1982; ii: 50.

37 Brownson RC, Reif JS. A cancer registry-based study of occupational risk for lymphoma, multiple myeloma and occupational risk for lymphoma, multiple

38 Pearce NE, Smith AH, Fisher DO. Malignant lymphoma and multiple myeloma linked with agricultural occupations in a New Zealand cancer registry-based study. $A m \mathcal{F}$ Epidemiol

39 Baker RJ, Nelder JA. Generalised linear interactive modelling (GLIM) system. Release 3. Oxford: Oxford Numerical Algorithms Group, 1978 